\title{
Chinese Agricultural Population Income in Economic Restructuring
}

\author{
Shifen Wang, Zelin Dai \\ School of Economics, Shanghai University, Shanghai, China \\ Email address: \\ daiz10679@163.com (Zelin Dai)
}

\section{To cite this article:}

Shifen Wang, Zelin Dai. Chinese Agricultural Population Income in Economic Restructuring. Humanities and Social Sciences. Vol. 3, No. 5, 2015, pp. 266-270. doi: 10.11648/j.hss.20150305.26

\begin{abstract}
With the continuous economic transforming, income and employment of the population of China's agricultural population has also undergone a significant change. Secondly, Population changes in agricultural income sources and employment of rural labor in different industries that reflects changes in the distribution of economic activities of farmers. Moreover, Changes in household income sources changes and rural labor force will help find ways to promote farmers' income growth. The conclusion is that farmers' income is mainly rely on labor from rural out, and the rural population engaged in what type of work is not directly related to the income.
\end{abstract}

Keywords: Structural Transformation of the Economy, Agricultural Income, Employment

\section{中国经济结构转型期农业人口收入研究}

\author{
王时芬, 戴泽琳 \\ 经济学院, 上海大学, 上海, 中国
}

\section{邮箱}

daiz10679@163. com（戴泽琳）

\begin{abstract}
摘要: 伴随经济结构的不断转型, 中国农业人口的收入与就业人口在行业间的配置也发生了显著变化。农业人口收入 来源的变化和农村劳动力在不同行业中的就业分布反映了农民经济活动的变化。研究农户收入来源的变化和农村劳动 力就业的变化有助于发现促进农民收入增长的途径。研究主要以经济结构转型为背景, 以农村居民家庭人均农业纯收 入与非农业纯收入的比值、第一产业就业人员相对于非第一产业就业人员比值等具体数据为自变量, 以中国农业人口 人均收入为因变量，建立线性回归模型来分析促进农业人口收入的原因，并最终为促进农民增收提供相关政策建议。 实证分析得出的主要结论是：农村人口收入的增加，和第一产业就业人员与非第一产业就业人员的比值呈负相关的关 系。从事农业生产的人员越少, 农村人口的收入增加越大。同时, 农村人口收入的增加, 和人均农业纯收入与人均非 农业纯收入的比例没明显的关系。简言之, 农民增收问题主要是靠劳动力从农村转移出去, 而与农村人口从事什么类 型的工作没有直接关系。
\end{abstract}

关键词: 经济结构转型, 农业人口收入, 就业

\section{1. 引言}

经济结构转型是指在经济产出中, 第一产业的比重逐 步下降, 第二产业和第三产业的比重不断上升。这是一个
国家现代化的必由之路。在此过程中, 社会结构也从农业 的、乡村的、封闭的传统社会向工业的、城镇的、开放的 现代社会转型。经济结构转型的目的是实现经济增长方式 的转变, 从而实现经济的高效、可持续增长。近年来, 中 
国经济社会现代化的步伐逐渐加快，以工业化、城市化、 市场化、信息化为内容的转型逐渐把中国纳入世界经济社 会发展的主流中。

中国是一个发展中大国, 农业历来被认为是安天下、 稳民心的战略产业。改革开放以来, 伴随着经济结构转型, 工业化、城镇化步伐的加快, 农村社会变迁的深度和广度 不断拓展, 农户收入也发生了变化。2013年中国农村居民 人均纯收入实际增长 $9.3 \%$, 农村贫困人口减少 1650 万人, 粮食产量超过 1.2 万亿斤, 实现 “十连增”。这些数据说 明伴随中国经济结构转型的进一步深入, 农业人口收入得 到改善。另一方面, 目前农村有许多人外出打工, 真正完 全从事农业生产和完全从农产品中获得收入的人口明显 减少。因此, 本文围绕经济结构转型中农业人口人均收入、 他们的收入结构与就业人员配置之间的关系进行研究, 以 确定中国农业人口收入的变化情况, 对于进一步提出促进 农户增收的相应措施具有重要的实践意义, 并能为促进农 民增收提供相关政策建议。

\section{2. 文献综述}

中国外研究者就经济转型期中国农户收入结构和农 村劳动力转移进行了相关探讨研究。

张凤龙和藏良 ${ }^{1}$ （2007）对中国农民收入结构进行研 究后得出, 工资性收入已成为农户收入增长的重要组成部 分。他们认为应从加大财政对农业的支持力度, 调整经济 结构, 加快农村富余劳动力向城市转移, 突破农村第二产 业和第三产业发展瓶颈, 大力发展农村教育事业这五个方 面着手来促进农民增收。张车伟 ${ }^{2}$ (2011) 分地区对农民 收入结构和增长变化进行考察得出, 农民收入增长来源出 现单一化, 由依靠家庭经营性收入转变为依靠劳动报酬性 收入（工资性收入）。周雪松和刘颖 ${ }^{3}$ (2012) 对中国农 民收入水平与收入结构两者之间的变动规律进行了实证 研究, 他们在分析了1978年以来农民收入结构的演变及各 地农业经济发展不平衡状况的基础上, 运用近 10年的统计 数据对农民收入结构演变趋势进行了模拟, 从农民收入组 成的四部分 (家庭经营性收入、工资性收入、财产性收入、 转移性收入) 提出了增加农民收入的政策措施。林锋峰等 ${ }^{4}$ （2006）在测度福建省城市化综合水平的基础上，运用 线性回归模型分析得出提高城市化水平有助于提高农民 的人均收入。廖丹青等 ${ }^{5}$ (2009) 研究认为, 城市化是影 响农民收入的主要因素, 城市化转移农村人口、缓解人多 地少的矛盾、提高劳动生产率从而增加农民收入。杨灿明

1 张凤龙、藏良: 《失地农民社会保障问题研究》 $[\mathrm{J}]$, 《行政与法》, 2007 , 第 11 期, 58-61页。

2 张车伟: 《中国收入分配存在的问题及对策建议》 $[\mathrm{J}]$, 《中国经贸 导刊》, 2011, 第5期, 17-19页。

3 周雪松、刘颖: 《中国农民收入结构演变及其启示》 [J], 《中国农 学通报》, 2012, 第14期, $210-213$ 页。

4 林锋峰、魏远竹、谢志忠: 《福建省城市化与提高农民收入的实证研 究》 $[\mathrm{J}]$, 福建论坛 (人文社会科学版) , 2006, 第1期, 116-119页。 5 廖丹青: 《我国农村人力资源开发与新时期新农村建设》 $[\mathrm{J}]$, 《科 教文汇》，2009，第1期，183-183页。
等 $^{6}$ (2011) 认为农民收入趋向多样化, 并从各个来源提 出了相应的增收政策。

\section{3. 理论研究}

\section{1. 经济结构转型期中国农业人口收入研究}

劳动力总是从产出效率低的行业向产出效率高的产 业转移。城市工业部门的劳动生产率高于农业部门的劳动 生产率。随着中国经济结构转型的进一步加深, 第二产业 和第三产业获得了长足的发展。农业人口收入的增长越来 越多的来自于第二、第三产业所带来的收入。中国经济结 构转型对农业人口收入的影响主要体现在农村人口和劳 动力减少、提供非农就业机会和收入、增加对初级农产品 需求、提高农产品附加价值等方面。另外, 城市规模的扩 大和人口扩张, 增加了对农产品的消费需求, 有助于实现 城乡之间良性经济循环。

人均纯收入是指农村常住居民家庭总收入中，扣除从 事生产和非生产经营费用支出、缴纳税款、上交集体提留 和推派等以后剩余的, 可用于直接进行生产性和非生产性 建设投资、生活消费和积蓄的那一部分收入。它是反映农 村居民实际收入水平的主要指标。本文选用农村居民家庭 人均纯收入作为评价农民收入水平的指标。

至2013年，农民增收实现了改革开放以来的首次 “十 年快”。据国家统计局数据, 农村居民人均纯收入达到 8896 元, 剔除价格因素实际增长 $9.3 \%$, 高出GDP实际增速 1.6 个百分点, 城乡居民收入之比连续 4 年下降, 由 2009 年的 3. 33:1下降到3.03:1, 农村居民人均纯收入实际增速高于 城镇居民人均可支配收入增速 2.3 个百分点。

表1 1999年以来农村居民家庭平均每人纯收入及收入构成变化（单位: 元）。

\begin{tabular}{|c|c|c|c|c|}
\hline & 人均纯收入 & $\begin{array}{l}\text { 人均农业纯收 } \\
\text { 入 } a_{1}\end{array}$ & $\begin{array}{l}\text { 人均非农业收 } \\
\text { 入 } a_{2}\end{array}$ & $A=a_{1} / a_{2}$ \\
\hline 2013 & 8895.9 & 2828 & 6067.9 & 0.47 \\
\hline 2012 & 7916.6 & 2106.8 & 5809.8 & 0.36 \\
\hline 2011 & 6977.3 & 1896.7 & 5080.6 & 0.37 \\
\hline 2010 & 5919 & 1723.5 & 4195.5 & 0.41 \\
\hline 2009 & 5153.2 & 1497.9 & 3655.3 & 0.41 \\
\hline 2008 & 4760.6 & 1427 & 3333.6 & 0.43 \\
\hline 2007 & 4140.4 & 1303.8 & 2836.6 & 0.46 \\
\hline 2006 & 3587 & 1159.6 & 2427.4 & 0.48 \\
\hline 2005 & 3254.9 & 1097.7 & 2157.2 & 0.51 \\
\hline 2004 & 2936.4 & 1056.5 & 1879.9 & 0.56 \\
\hline 2003 & 2622.2 & 885.7 & 1736.5 & 0.51 \\
\hline 2002 & 2475.6 & 866.7 & 1608.9 & 0.54 \\
\hline 2001 & 2366.4 & 863.6 & 1502.8 & 0.57 \\
\hline 2000 & 2253.4 & 833.9 & 1419.5 & 0.59 \\
\hline 1999 & 2210.3 & 918. 3 & 1292 & 0.71 \\
\hline
\end{tabular}

数据来源: 《中国统计年鉴2013》

6 杨灿明、孙群力: 《中国居民收入差距与不平等的分解一一基于 2010 年问卷调查数据的分析》 $[\mathrm{J}]$, 《财贸经济》, 2011, 第11期, 51-56页。 
据农业部介绍, 当前农民增收形势总体平稳，收入来 源结构正发生积极变化，增收机制日趋完善，增收良好态 势仍然继续。农民收入结构继续优化。工资性收入 4025 元, 占人均纯收入的 $45.2 \%$, 超越家庭经营纯收入成为农 民收入的首要来源; 家庭经营纯收入 3793 元, 占 $42.6 \%$, 同比下降 2 个百分点; 转移性收入、财产性收入分别占 $3.3 \%$ 、 $8.9 \%$, 同比均提高 0.2 个百分点; 第一产业收入占 $31.8 \%$, 下降2.6个百分点。同时, 农民消费水平继续提高。2013 年，农村居民人均消费支出 6626 元，同比增长 $9 \%$ ，增幅比 城镇居民人均现金消费支出增速快 3.6 个百分点。（数据 来源于新浪财经)

为了使研究更方便简洁, 在本文中, 农业人口收入来 源简化为农业收入与非农业收入两个部分。农业收入与非 农业收入相比即可得出近年来中国农业人口收入结构的 变化趋势（如表1所示）。

\section{2. 经济结构转型期中国农业人口就业结构变化的研究}

从表1来看, 农业人口收入来源结构的变化也从侧面 反映了农业人口的就业结构变化。从本质上讲, 农民收入 问题就是一个就业问题。在改革开放以前，中国政府通过 户籍制度等政策法规严格控制城乡间人口流动, 农村非农 就业机会几乎为零。改革初期, 家庭联产承包责任制和农 产品价格的逐步放开极大地激发了农民的农业生产积极 性。从 80 年代中后期开始, 由于日益严峻的人地矛盾以及 农业劳动生产率的提升, 产生大量的农村剩余劳动力。同 时, 城乡收入差距的不断扩大, 农业劳动边际收入进一步 递减, 大量农村劳动力纷纷离开土地, 迁移到城市做农民 工, 非农就业得到迅速发展。农户非农就业的变化也在一 定程度上反映了经济结构转型中城乡劳动力市场一体化 发展的状况。表2列示了1999年至2013年全国就业人员、 第一产业的就业人员和非第一产业就业人员的统计数据。

表2 1999年一 2013 年人口与就业数据（万人）。

\begin{tabular}{|c|c|c|c|c|}
\hline & $\begin{array}{l}\text { 就业人员 } \\
\text { 合计 }\end{array}$ & $\begin{array}{l}\text { 第一产业就 } \\
\text { 业人员 } b_{1}\end{array}$ & $\begin{array}{l}\text { 非第一产业就 } \\
\text { 业人员 } \mathrm{b}_{2}\end{array}$ & $\mathrm{~B}=\mathrm{b}_{1} / \mathrm{b}_{2}$ \\
\hline 2013 & 76977 & 24171 & 52806 & 0.4577 \\
\hline 2012 & 76,704 & 25,773 & 50,931 & 0.5060 \\
\hline 2011 & 76,420 & 26,594 & 49,826 & 0.5337 \\
\hline 2010 & 76,105 & 27,931 & 48,174 & 0.5797 \\
\hline 2009 & 75,828 & 28,890 & 46,938 & 0.6154 \\
\hline 2008 & 75,564 & 29,923 & 45,641 & 0.6556 \\
\hline 2007 & 75,321 & 30,731 & 44,590 & 0.6891 \\
\hline 2006 & 74,978 & 31,941 & 43, 037 & 0.7421 \\
\hline 2005 & 75,825 & 33,970 & 41,855 & 0.8116 \\
\hline 2004 & 75,200 & 35,269 & 39,931 & 0.8832 \\
\hline 2003 & 74,432 & 36,546 & 37,886 & 0.9646 \\
\hline 2002 & 73,740 & 36,870 & 36,870 & 1. 0000 \\
\hline 2001 & 73,025 & 36,513 & 36,512 & 1.0000 \\
\hline 2000 & 72,085 & 36,043 & 36,042 & 1. 0000 \\
\hline 1999 & 71,394 & 35,768 & 35,626 & 1. 0039 \\
\hline
\end{tabular}

数据来源: wind资讯

从表 2 中数据可以看出, 中国第一产业就业人员从 1999年以来至2013年不断减少, 同时, 第一产业就业人员 对非第一产业人员的比例也在不断降低。
根据世界银行在1998的估算，如果中国的农业人口向 非农部门流动的模式与其他国家相类似的话，那么人均 GDP每增长 $10 \%$, 保守地估计会使农业部门的就业减少 $3.1 \%$ 。 有研究表明, 中国实施改革开放政策以来的经济增长有 $16 \%$ $-20 \%$ 的份额是来源于劳动力流动和劳动力重新配置所导 致的生产率提高（蔡昉和王德文, 2006） ${ }^{7}$ 。

因此, 劳动力由农村向城市、由农业向非农业的流动 对于中国未来经济增长有着举足轻重的意义。同时, 由此 带来的经济增长也将促进地区间经济持续健康发展, 从而 进一步加快经济结构转型深入的步伐。

\section{4. 实证分析}

为了从定量角度进一步说明上述关系, 我们将收入增 长成分的变化与劳动力配置变化情况联系起来, 观察收入 增长的成分变化与劳动力配置结构对农民收入增长的作 用机制和影响程度。根据农村居民家庭人均收入与 $\mathrm{A}$ (农村 居民家庭人均农业纯收入/农村居民家庭人均非农业纯收 入）、B（第一产业就业人员/非第一产业就业人员）三者 关系, 本文将建立回归模型并进行参数估计。

\section{1. 数据来源与处理}

数据来源于《中国统计年鉴2014》国家统计局与wind 资讯, 数据选自1999年至2013年农村居民家庭人均纯收入、 农村居民家庭人均农业纯收入以及就业人员合计与第一 产业就业人员人数统计。

用农村居民家庭人均纯收入减去农村居民家庭人均 农业纯收入得到农村居民家庭人均非农业纯收入，从而得 出人均农业纯收入相对于非农业纯收入的比值A。同理, 用就业人员合计减去第一产业就业人员得到非第一产业 就业人员数, 进而得到第一产业就业人员相对于非第一产 业就业人员的比值B。用农村居民家庭人均名义收入被农 村居民消费价格指数调整后得到农村居民家庭人均实际 收入Y（见表3）。

表3 解释变量与被解释变量。

\begin{tabular}{llll}
\hline 年份 & $\mathrm{A}$ & $\mathrm{B}$ & $\mathrm{Y}$ (万元) \\
\hline 1999 & 0.71 & 1.003985 & 0.2244 \\
2000 & 0.59 & 1.000028 & 0.2256 \\
2001 & 0.57 & 1.000027 & 0.2348 \\
2002 & 0.54 & 1 & 0.2486 \\
2003 & 0.51 & 0.964631 & 0.2581 \\
2004 & 0.56 & 0.883248 & 0.2802 \\
2005 & 0.51 & 0.811612 & 0.3185 \\
2006 & 0.48 & 0.742175 & 0.3535 \\
2007 & 0.46 & 0.68919 & 0.3928 \\
2008 & 0.43 & 0.655617 & 0.4470 \\
2009 & 0.41 & 0.655617 & 0.5169 \\
2010 & 0.41 & 0.579794 & 0.5713 \\
2011 & 0.37 & 0.533737 & 0.6595 \\
2012 & 0.36 & 0.506038 & 0.7724 \\
2013 & 0.47 & 0.4577 & 0.8793 \\
\hline
\end{tabular}

7 菜昉、王德文等: 《农村发展与增加农民收入》 [M] , 中国劳动社会 保障出版社，2006一版一印。 
伴随中国经济结构转型的推进, 中国农业人口收入中 来自于农业收入的比重不断下降, 就业人口也不断从第一 产业向非第一产业转移。因此, 我们可以用 $\mathrm{A}$ 与 $\mathrm{B}$ 作为衡量 中国经济结构转型特征的解释变量, Y为被解释变量, 通 过建立与农业人口收入的关系的模型, 得出经济结构转型 对中国农业人口的收入增长的贡献因素。

\section{2. 模型建立}

用Eviews作出A与Y的散点图:

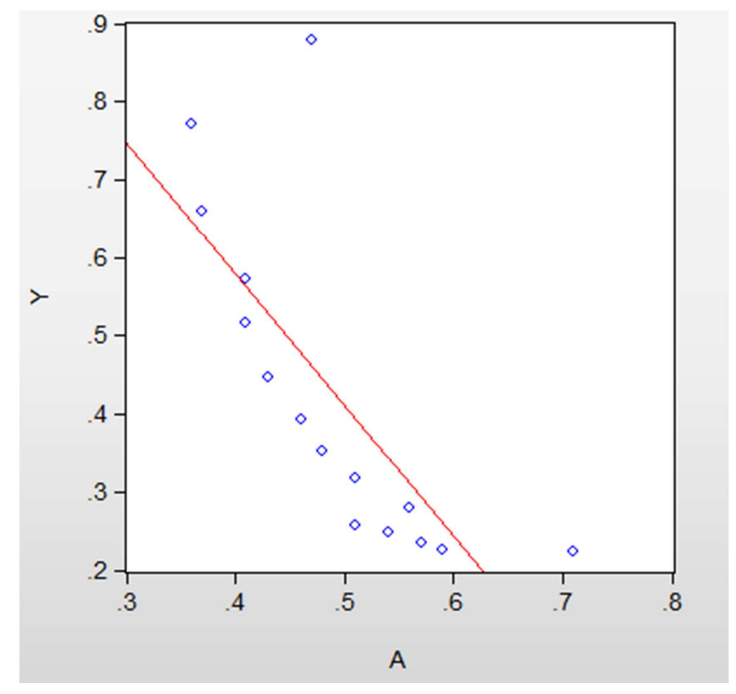

图1 A与Y的散点图。

同样, 用Eviews作出B与Y的散点图:

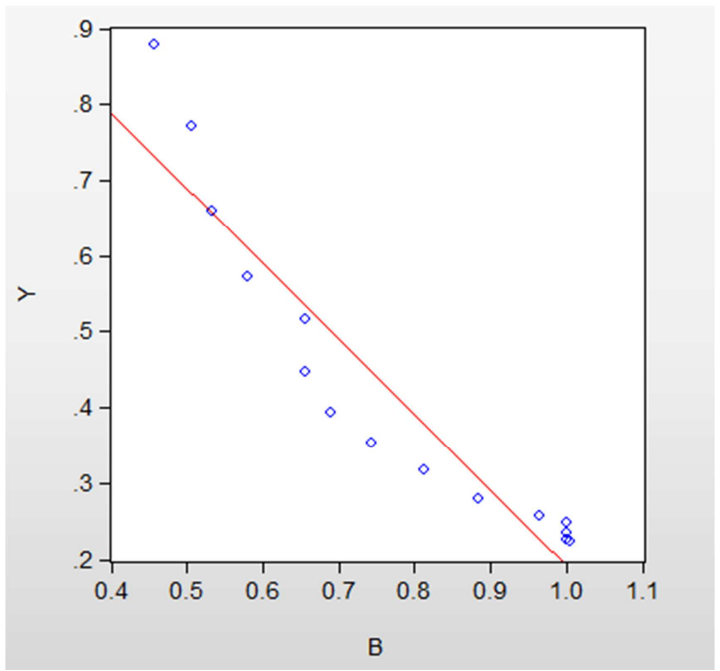

图2 B与Y的散点图。

由两张散点图可以看出, $A 、 B$ 与 $Y$ 之间可能存在线性 关系，故建立二元线性回归模型：

$$
Y=\beta_{0}+\beta_{1} A+\beta_{2} B+\mu
$$

其中, $\beta_{0}$ 为截距项, $\beta_{1}$ 与 $\beta_{2}$ 为回归系数, $u$ 为残 差项。

\section{3. 实证结果}

将解释变量A、B和被解释变量Y的数值代入Eviews7.0 软件, 得到最小二分法回归结果如下：

表4 Eviews 运算结果。

\begin{tabular}{lllll}
\hline Dependent Variable: Y & Sample: 1999 2013 & $\begin{array}{l}\text { Included } \\
\text { observati } \\
\text { ons: 14 }\end{array}$ \\
\hline Variable & Coefficient & Std. Error & t-Statistic & Prob. \\
\hline C & 1.111178 & 0.109581 & 10.14027 & 0.0000 \\
A & 0.400886 & 0.398359 & 1.006344 & 0.3341 \\
B & -1.153283 & 0.186249 & $\begin{array}{l}-6.192156 \\
\text { Adjusted }\end{array}$ & 0.0000 \\
R-squared & 0.892510 & & $\begin{array}{l}\text { R-squared } \\
\text { Prob(F- } \\
\text { statistic) }\end{array}$ & 0.874595 \\
F-statistic & 49.81907 & & \multicolumn{3}{c}{000002} \\
\hline
\end{tabular}

由回归结果可以得到回归方程为:

$$
\hat{y}_{i}=1.111178-0.400886 A-1.153283 B
$$

由Ad justed R-squared和F值可知, 模型拟合情况良 好, 线性关系显著。

在 $95 \%$ 的置信度下, $\beta_{0}$ 和 $\beta_{2}$ 的显著, 因而 $\beta_{1}$ 不显著。 $\beta_{2}$ 为 -1.153283 , 说明 $\mathrm{B}$ 每减少一个百分点, $\mathrm{Y}$ 将增加 1. 153283 万元。

实证检验的结果表明, 农村人口收入的增加, 和第一 产业就业人员与非第一产业就业人员的比值呈负相关的 关系。也就是说, 从事农业生产的人员越少, 农村人口的 收入增加越大。农民增收主要是靠农业生产效率的提高导 致劳动力从农村转移出去, 从事其他行业的工作。同时, 农村人口收入的增加, 和人均农业纯收入与人均非农业纯 收入的比例没有显著的关系。从表1中, 我们可以得到一 个可能的解释: 在1999-2005的7年中, 人均农业纯收入 与人均非农业纯收入相比, 都占 $50 \%$ 以上, 略有波动, 说 明那时的人均农业纯收入和人均非农业纯收入是同步增 长的。2006年以后这个比例才开始小于 $50 \%$ 。这个现象告 诉我们, 只要农业纯收入保持增长, 务农照样可以增加收 入。

\section{5. 结论及政策建议}

现代化过程中的经济结构转型实质上是一个工业化、 城镇化的过程。随着经济的发展, 国民经济的三个产业相 对比重发生改变, 从第一产业到第二产业、再到第三产业 渐次推进。与此相应, 就业结构也发生变化, 从事第一产 业的人数相对于从事制造业的人数趋于下降; 进而, 从事 制造业的人数相对于从事服务业的人数趋于下降。在经济 结构转型和收入增长的过程中, 农村人口收入来源与就业 结构发生变化, 其中农村人口的人均农业纯收入相对于非 农业纯收入不断下降; 第一产业就业人数相对于非第一产 业就业人数不断下降。 
农村居民人均实际收入为因变量, 农村居民人均农业 纯收入与非农业纯收入的比例、以第一产业就业人数与非 第一产业就业人数的比例为 2 个自变量进行实证研究, 结 果显示人均农业纯收入与非农业纯收入的比例对农村人 均收入的增长没有显著影响; 而第一产业就业人数与非第 一产业就业人数的比例每下降 1 个百分比, 农村居民人均 年实际收入将增加 1.1533 万元。

农村人口收入的来源情况对农业人口收入的影响并 不显著, 他们的收入与农民从事什么工作没有直接关系, 而与农业劳动力数量与非农劳动力数量的比例有关。从事 农业的劳动力数量越少, 农村人口收入也就越高。简而言 之, 提高农业人口收入的关键是提高农业劳动生产率。农 业劳动生产率提高了, 一来可以使更多的农村劳动力从土 地中解放出来, 从事其他职业, 从而提高农村的人均收入。 二来, 农业劳动生产率提高, 种地有利可图, 从事农业生 产照样可以提高农村的人均收入。

对于中国这样一个农村人口仍很庞大的国家，农村人 口的收入问题已不仅仅是一个简单的 “三农” 问题。必须 将农民收入的提高放到国民经济发展的宏观层面来考虑, 把促进农村人口收入增长与农业生产率的提高, 也与加快 工业化、城市化步伐相联系。

首先, 要以农业科研为引领, 推动农业生产专业化、 深加工化, 提高农业生产率和农产品价值。农民以农为本, 离开了农业也就不能算作职业意义上的农民。因此，农业 收入仍然是农业人口收入的基础。所以，在保护和提高农 业综合生产能力的前提下，应按照高产、优质、高效、生 态、安全的要求, 走精细化、集约化、产业化的道路, 注 重农产品深加工, 促进农业生产结构不断优化升级, 不断 提高农产品的附加值。

其次, 大力发展二、三产业, 促进农村劳动力向非农 产业转移。不论农村人口是进城还是就地转移到其他产业, 农民从单纯的农业生产中解放出来, 是促进农村人口收入 增长的重要方法。大城市的容量毕竟有限, 所以大力发展 农村二、三产业使得农民“离土不离乡”是提高农民收入、 吸收过剩的农村劳动力的必然选择。政府应制定政策鼓励 农村个私经济特别是微、小型企业的发展, 并在金融等方 面予以支持; 同时应积极发展农村服务业, 特别是餐饮、 旅游业等行业。农村二、三产业的发展, 不仅能创造非农
就业机会, 同时也扩大了对农产品的需求, 有利于推动第 一产业的增长。

\section{参考文献}

[1] 张风龙、藏良: 《失地农民社会保障问题研究》 $[\mathrm{J}]$, 《行 政与法》，2007，第11期，58-61页。

[2] 张车伟: 《中国收入分配存在的问题及对策建议》 $[J]$, 《中 国经贸导刊》，2011，第5期，17-19页。

[3] 周雪松、刘颖: 《中国农民收入结构演变及其启示》 [J]， 《中国农学通报》，2012，第14期，210-213页。

［4］林锋峰、魏远竹、谢志忠: 《福建省城市化与提高农民收 入的实证研究》 [J], 福建论坛 (人文社会科学版), 2006, 第1期, 116-119页。

[5] 廖丹青: 《中国农村人力资源开发与新时期新农村建设》 $[J] ， 《$ 科教文汇》, 2009, 第1期, 183-183页。

[6] 杨灿明、孙群力: 《中国居民收入差距与不平等的分解一一 基于 2010 年问卷调查数据的分析》 $[\mathrm{J}]$, 《财贸经济》, 2011, 第11期, 51-56页。

［7］菜昉、王德文等：《农村发展与增加农民收入》 [M]，中国 劳动社会保障出版社, 2006一版一印。

[8] 韩俊, 改革开放以来农村经济社会转型研究 $[J]$ 经济研究导 刊, 2008, Issue 2, pp. 1-5。

[9] 白重恩, 钱震杰, 国民收入的要素分配: 统计数据背后的故 事 [J] 经济研究, 2009, 第3期, 27-41。

[10] 范剑勇, 张涛, 结构转型与地区收玫: 美国的经验及其对中 国的启示 [J]世界经济 2003, 第1期, 42-48。

[11] 李勋来, 李国平, 农村劳动力转移模型及实证分析 [J]财经 研究, 2005, 第31期, 78-85。

[12] 卢布, 陈印军, 吴凯, 我国农业结构现状及未来变化趋势研 究 $[J]$ 农业技术经济, 2005, 第2期, 52-57。 